\section{Electron Microscopy in Australia}

Paul Munroe, University of New South Wales, Sydney Australia p.munroe@unsw.edu.au

In spite of its relatively small population, about 20 million people Australia has, across a large number of fields, made significant contributions to science and technology. Expressed statistically, approximately $2.4 \%$ of published science research has its origins 'down-under'. Electron microscopy is no exception. Indeed, a significant number of pioneering developments in microscopy (and prominent microscopists) have originated from Australia. For example, early developments in environmental scanning electron microscopy had their birth at this university (through Viv Robinson and Gerry Danilatos) in the 1970's Leading figures such as David Cockayne, John Cowley, John Spence, Michael O'Keefe once (still?) called Australia home.

Contrary to the popular image of a nation dominated by a rugged Outback, deserts and Steve Irwin. Australia is one of the most urbanised countries in the world. A very high fraction of the population lives in the various state capital cities. These cities are themselves geographically widely separated and interstate travel is best achieved by (often long) flights. It is not surprising, therefore, to find the vast majority of Australian universities and research centres to be located in these cities.

At present, there are about 400 electron microscopes located in Australia. The majority of these are situated in universities. A smaller number are operated by government laboratories (for example the Commonwealth Scientific Industry Research Organization (CSIRO) and the Australian Nuclear Science and Technology Organization (ANSTO)). There are, however, relatively few microscopes located within private industry. In most cases, the corporate sector will choose to access public sector microscopes when the need arises.

In most institutions electron microscopes tend to be clustered into a single central campus facility, rather than dispersed across individual departments or sequestered in the fiefdoms of individual researchers. Almost all of the large research-oriented universities operate such central facilities. This has the advantage of producing, in each case, a critical mass of activity. Most of these centres operate ten or more instruments and many have ten or more staff members. This means that each centre can offer researchers in their institutions a wide range of facilities, and have them supported by staff who have considerable expertise in specific techniques. These centres each typically support several hundred research programs and they have been shown to underpin about $15 \%$ of the experimental research published from each institution. In addition, Australian microscopists have contributed significant fundamental research in developing microscopy techniques, for example convergent beam diffraction, ALCHEMI and variable pressure SEM.

Government funding for new instruments is tight and the various schemes available are highly competitive. Significant emphasis is placed on the sharing of resources between institutions and applicants are strongly encouraged to form consortia and make joint applications. In response to this, groups of institutions in some cities have formed into collaborative centres to formally share their instrumentation. An example of this is the Western Australian Centre for Microscopy (WACM), which formally combines the resources of four Perth-based universities. Researchers within these institutions are therefore able to access a much wider range of instruments.

The relatively small number of instruments in Australia can often mean support services and expertise are thinly stretched. There may be only one or two microscopes of a particular make and model in the country. As a consequence, service engineers are often trained in a wide range of instruments and spare parts must often be sourced from overseas. Expertise in a particular technique or to solve a specific problem may be difficult to locate. However, through electronic-based resources such as the 'Microscopy list server' and e-mail to overseas colleagues, this has become much less of a problem in recent years.

The professional body associated with overseeing electron microscopy is the Australian Microscopy and Microanalysis Society. The principal role of this society is to foster and promote mic

Australia. It does this largely through representations to assorted arms of government, through various committees of professional organizations, and the hosting of a biannual conference. This meeting typically attracts about 400 attendees and combines presentations and posters with workshops and user group meetings. An important role of this meetings is not only the dissemination of scientific research, but to act as a forum for practioners across the country to get together, interact, learn new skills and compare notes. Workshops on new and developing techniques always prove highly popular. More information on the society can be found at www.microscopy.org.au. Associated with this society are a number of satellite societies with special interests in, for example, microanalysis or scanning probe microscopy. Each of these societies organises their own smaller meetings. This society is also affiliated with the Microscopy Society of America. As a result of that association, the 2005 'Microscopy and Microanalysis' conference, to be held in Hawaii, will have many symposia chaired by Australian researchers. These symposium chairs reflect strongly on the expertise in microscopy that exists in Australia across a wide range of topics.

A recent and exciting development was Federal government's agreement to provide funding for the creation of the Nanostructural Analysis Network Organization (NANO) Major National Research Facility. Total funding for this origination is about Aus $\$ 20$ million over five years. The network seeks to combine the centres of excellence in microscopy at five leading research universities to create the national peak facility for microscopy and microanalysis in Australia. NANO combines the resources and expertise from centres for microscopy at the Universities of Sydney, New South Wales, Queensland, Melbourne and Western Australia. The network allows Australian researchers access to the facilities in these laboratories. This is facilitated through a Travel and Access Program that assists researchers with the costs of travelling to the various nodes of NANO. The focal point of the network consists of four high-end instruments of sufficient cost and complexity that they are likely to be the only such instruments located in the country. These instruments are a $300 \mathrm{kV}$ Cryo-FEG TEM at the University of Queensland, a NanoSIMS at the University of Western Australia, a Dual Beam Analytical FIB to be located at the University of New South Wales and a 3D Atom Probe to be located at the University of Sydney. It is pertinent to note that several of these instruments are predominantly based on ion beams, rather than electron beams, and provide the capability for three-dimensional analysis. Further details about NANO can be found at the network's website www.nano.org.au.

In summary, Australia boasts a small, but enthusiastic microscopy community. It is one that has been pivotal in both supporting a wide range of science and technology research and in the development of fundamental microscopy research.

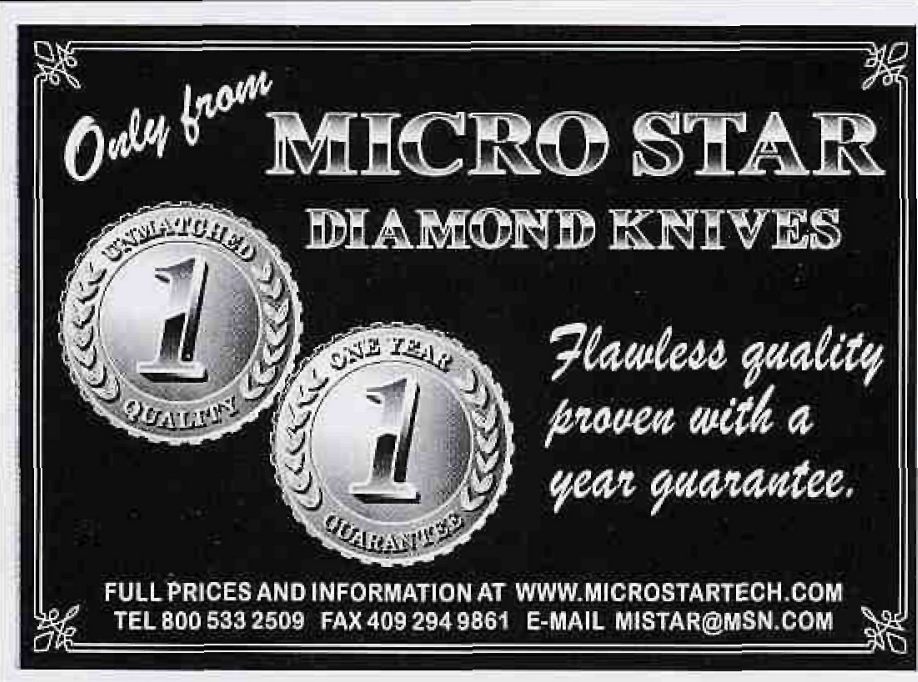

